\title{
You Never Know What You Might Find - Tracheo-Esophageal Fistula from Extrusion of a Spinal Fusion Fixation Screw
}

\author{
Jeffrey B. Hoag ${ }^{a, b}$ David P. Visco ${ }^{a}$ Mark E. Lund ${ }^{a, b}$ \\ ${ }^{a}$ Cancer Treatment Centers of America, Eastern Regional Medical Center, and brexel University College of \\ Medicine, Philadelphia, Pa., USA
}

\section{Case Report and Review}

A 41-year-old male with hepatobiliary adenocarcinoma metastatic to the cervical and thoracic spine presented with cough, copious sputum production and respiratory failure. Fourteen months antecedent, anterior fusion of C-7 to T-1 and posterior spine stabilization with external rod fixation for a pathologic fracture was performed. A chest radiograph demonstrated hardware in an appropriate position (fig. 1a). Computed tomography displayed displacement of the anterior fusion plate (AFP) and fix-
Fig. 1. a Initial posteroanterior radiograph. b Displacement of the AFP and fixation screws abutting the membranous trachea. c TEF at the margin of the left mid trachea. d Locking head of the anterior plate screw visible with respiration.
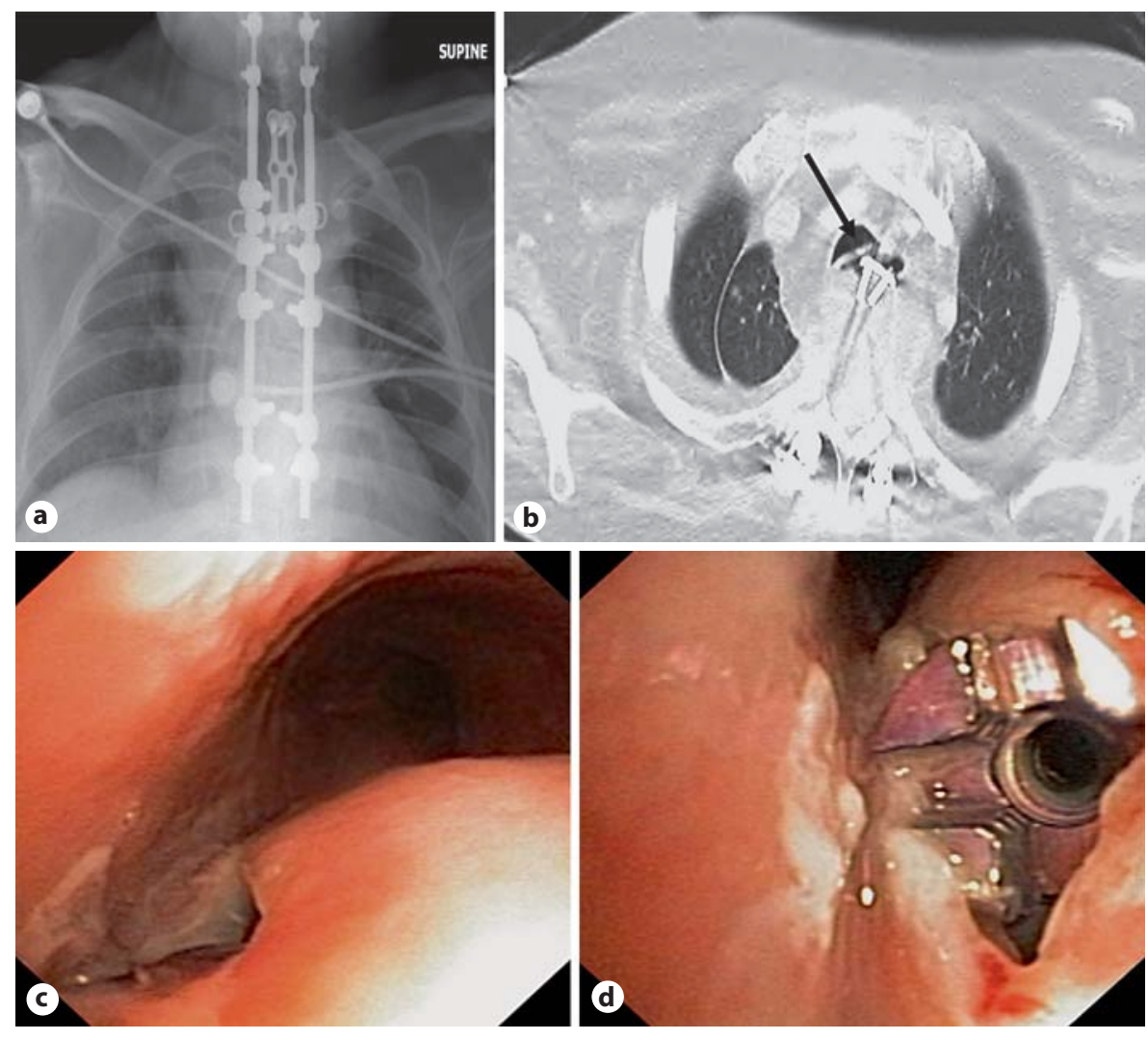

\section{KARGER}

Fax +4161306 1234

E-Mail karger@karger.ch

www.karger.com
(C) 2009 S. Karger AG, Basel

0025-7931/10/0796-0506\$26.00/0

Accessible online at:

www.karger.com/res
Mark E. Lund, MD, FCCP

Division of Pulmonary, Critical Care, and Sleep Medicine Drexel University College of Medicine, 245 N. 15th Street Mail Stop 107, NCB 12th Floor, Philadelphia, PA 19102 (USA)

Tel. +1 215762 7011, Fax +1 215762 8728, E-Mail mlund@drexelmed.edu 
ation screws (fig. 1b). The oblique orientation of the AFP with protruding left-sided fixation screws led to anterior compression of the esophagus and effacement of the membranous trachea. Fiberoptic bronchoscopy was performed with consideration of a tracheal stent placement. In the left posterior trachea, $5 \mathrm{~cm}$ distal to the subglottic shelf at the margin of the cartilaginous and membranous portions, copious pus emanated from a trachea-esophageal fistula (TEF) (fig. 1c). Suctioning revealed a 1-cm TEF, and the locking head of the AFP screw was visible (fig. 1d). Copious secretions causing symptomatic bronchorrhea dictated placement of an airway stent. The patient died in hospice 4 weeks later.
Anterior cervical fusion rarely leads to airway compromise. Causes of airway compromise may include perivertebral soft tissue swelling, dural leak with cerebrospinal fluid collections, compressive hematoma, and screw protrusion causing abscess formation, as well as phrenic nerve disturbances due to perivertebral swelling or direct injury $[1,2]$. We report, to our knowledge, the first case of AFP fixation screw dislodgement leading to TEF and respiratory failure. Due to our patient's advanced metastatic disease, airway stenting with a self-expanding metallic stent provided palliation and correction of respiratory derangement.

\section{References}

TEF from Extrusion of a Spinal Fixation Screw
1 Wong DT, Fehlings MG, Massicotte EM: Anterior cervical screw extrusion leading to acute upper airway obstruction: case report. Spine 2005; 15:E683-E686.
2 Fujiwara $\mathrm{H}$, Nakayama $\mathrm{H}$, Takahashi $\mathrm{H}$, Shimizu M, Hanaoka K: Postoperative respiratory disturbance after anterior cervical fusion. Masui 1998;47:475-478. 